\title{
RECUPERAÇÃO DE ACETONA EM RESÍDUOS LABORATORIAIS: UMA ABORDAGEM SOBRE ASPECTOS DA GESTÃO, OPERACIONAIS E DA EFICIÊNCIA AMBIENTAL
}

\author{
Guilherme Furlan Coletti*a,®, Glauco Arnold Tavares ${ }^{\mathrm{a}}$ e José Albertino Bendassolli ${ }^{\mathrm{a}}$ \\ ${ }^{a}$ Centro de Energia Nuclear na Agricultura, Universidade de São Paulo, 13416-000 Piracicaba - SP, Brasil
}

Recebido em 06/02/2019; aceito em 26/03/2019; publicado na web em 22/04/2019

\begin{abstract}
ACETONE RECOVERY IN LABORATORIES WASTES: AN APPROACH OF ASPECTS OF MANAGEMENT, OPERATION AND ENVIRONMENTAL EFFICIENCY. The objective of this work was to exclusively improve the management of wastes constituted mainly by organic solvents, due to the opportunities for improvements in the processing of such substances in the institution where the studies were realized. By means of the tests carried out in the distillation system using acetone as a reference, advantages and disadvantages were found with increasing/decreasing the temperature used in the process. From the use of gas chromatography, it was possible to obtain a more precise control of the quality of the recovered product and also to verify the high efficiency of the distillation process in the separation of the solvent from the other contaminants present in the waste. And in terms of comparison of treatments, distillation proved to be environmentally more sustainable and about 8 times more economical than incineration.
\end{abstract}

Keywords: chemical wastes; distillation; gas chromatography; environmental and financial analyzes.

\section{INTRODUÇÃO}

Indiscutivelmente as indústrias, principalmente químicas, são as maiores geradoras de resíduos químicos, sendo comumente associada a elas a responsabilidade pelos impactos causados ao meio ambiente decorrentes da contaminação e/ou poluição resultante de qualquer evento de descarte irregular de compostos químicos tóxicos. Consequentemente, as mesmas são os principais alvos de fiscalização dos órgãos ambientais.

Por outro lado, os laboratórios de universidades e instituições de ensino e pesquisa também são geradores de resíduos químicos, porém em escala muito menor, motivo esse que não justifica o desprezo dos potenciais danos ambientais com a destinação incorreta de seus resíduos. Esse tema se torna ainda mais relevante quando se leva em consideração a postura e a coerência que esses centros educacionais devem apresentar perante a sociedade, seja através da disseminação do conhecimento, da prestação de serviço ou na formação de futuros profissionais, tornando, dessa forma, imprescindível a criação de mecanismos para a gestão e gerenciamento de seus resíduos. ${ }^{1}$

Felizmente, encontram-se na literatura trabalhos relacionados à implantação de programas de gerenciamento de resíduos químicos em universidades e instituições de ensino e pesquisa, evidenciando uma tendência de preocupação cada vez maior com assuntos relacionados as questões ambientais nessas instalações. ${ }^{1-9}$

O Centro de Energia Nuclear na Agricultura da Universidade de São Paulo (CENA/USP) possui, desde 2001, um programa de gerenciamento de resíduos químicos e águas servidas, a partir do qual vários trabalhos de pesquisa nessa área do conhecimento vêm sendo realizados, abordando temas que discutem desde o desenvolvimento de métodos analíticos mais limpos, até ações que visam a identificação, reaproveitamento ou tratamento de resíduos. ${ }^{10-17} \mathrm{~A}$ relação de resíduos químicos gerados pelos laboratórios do CENA é bastante diversificada, incluindo solventes (etanol, metanol, hexano, acetonitrila, tolueno, acetona, entre outros) soluções inorgânicas diversas $\left(\mathrm{NH}_{3} \mathrm{aq}, \mathrm{SO}_{2} \mathrm{aq}\right.$, ácidos, bases, soluções contendo metais, entre outras) e resíduos sólidos (óxidos de cobre, perclorato de magnésio, géis de agarose ou poliacrilamida, etc). ${ }^{17}$

*e-mail: gcoletti@yahoo.com.br
Valendo-se dessa breve descrição do atual cenário dos resíduos químicos gerados no CENA, o objetivo deste trabalho foi realizar uma análise criteriosa e promover o aprimoramento da gestão dos resíduos constituídos majoritariamente por solventes orgânicos, devido às possibilidades de otimização e implantação de novos procedimentos analíticos para um maior controle da qualidade de tais substâncias na Instituição. Deve-se ressaltar, entretanto, que atualmente as duas opções de destinação ${ }^{18}$ aplicadas a esses resíduos são a destilação (quando há interesse de reutilização dos solventes recuperados) e a incineração (tratamento externo, realizados em incineradores licenciados), sendo pertinente, nesse caso, a realização de uma análise comparativa em termos financeiros e ambientais dessas duas formas de destinação, fazendo uso do software de uso livre Ecosolvent para fins de avaliação de impacto ambiental, ferramenta essa que vem sendo bastante empregada em pesquisas dessa natureza. ${ }^{19-23}$

\section{PARTE EXPERIMENTAL}

\section{Materiais utilizados}

Os testes de destinação dos resíduos, em processo físico, foram conduzidos em um sistema dedicado para destilação e recuperação de solventes dimensionado para atender à demanda institucional e detalhado na Figura 1. As análises foram realizadas utilizando um cromatógrafo gasoso marca Agilent modelo 7820A com detector por ionização de chama (FID), empregando coluna HP-INNOWAX (fase estacionária polietilenoglicol) de $30 \mathrm{~m}$ de comprimento, $0,25 \mathrm{~mm}$ de diâmetro e $0,15 \mu \mathrm{m}$ de espessura do filme.

Todos os solventes empregados foram grau pró-análise, notadamente para as moléculas de acetona 99,50\% (Synth), acetonitrila 99,90\% (Tedia), butanol 99,40\% (Vetec), clorofórmio 99,80\% (J.T Baker), diclorometano 99,90\% (Tedia), etanol 99,50\% (Carlo Erba), isopropanol 99,80\% (Merck), metanol 99,90\% (J.T Baker) e tolueno 99,50\% (Merck). Insumos como água desionizada, gases especiais pressurizados (Hidrogênio 4.5 FID, Nitrogênio 4.6 e Ar Sintético 5.0 FID) e as soluções residuais contendo acetona também foram utilizados. Em relação à vidraria e demais equipamentos e acessórios empregados, destacam-se: pipetas, pipetadores, frascos para amostragens diversos, provetas, bequeres, microseringas, funis, balanças de 


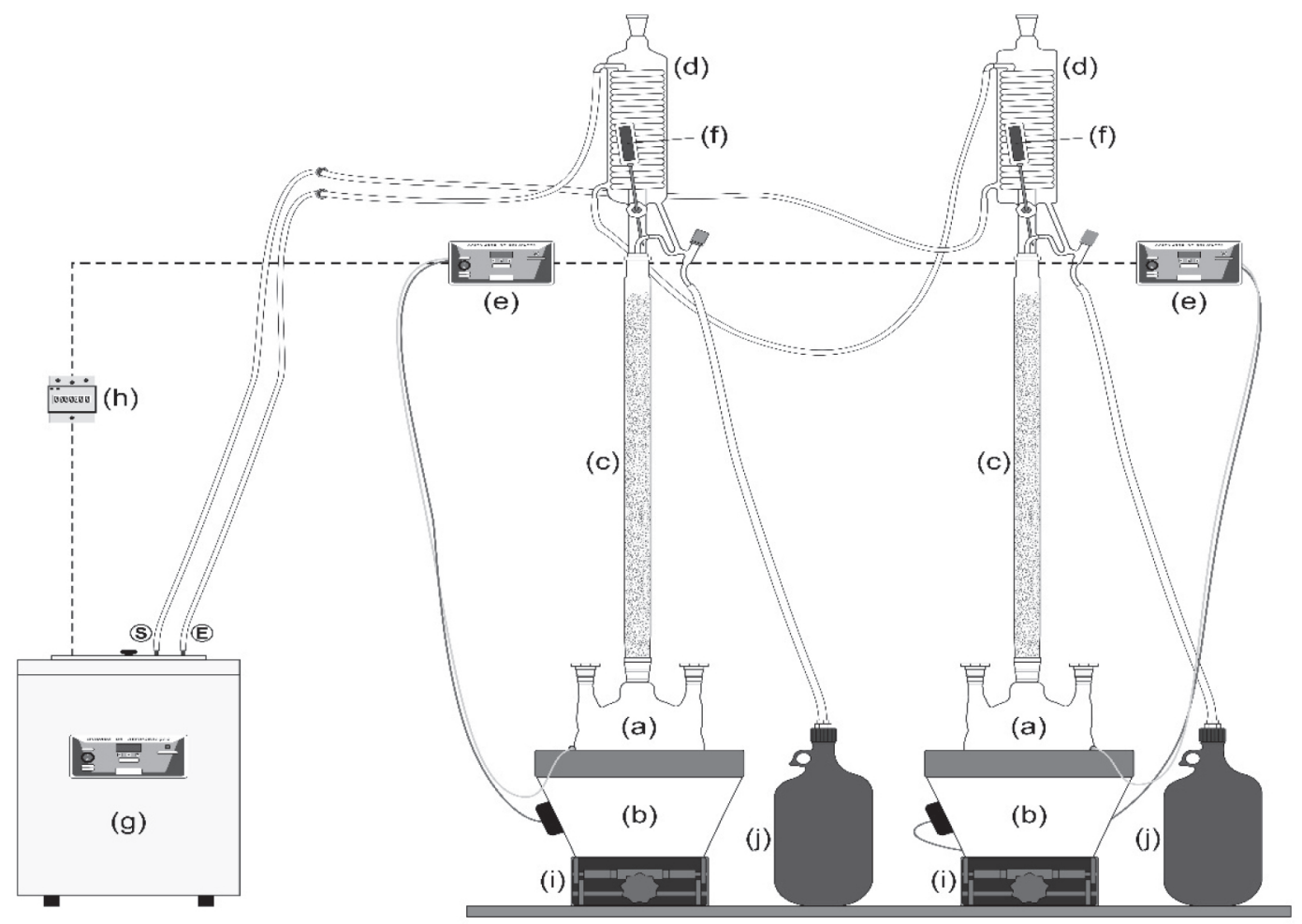

Figura 1. Representação ilustrativa do sistema de destilação para recuperação de solventes, dotado de: (a) balões Pyrex de três vias e 5 L de capacidade volumétrica; (b) mantas aquecedoras Fisaton; (c) colunas Pyrex preenchidas com anéis de Raschig; (d) condensadores Pyrex tipo serpentina; (e) sistemas digitais de controle de aquecimento Biothec modelo BTDS5; $(f)$ termômetros digitais Incoterm; ( $g$ ) banho ultratermostatizado para recirculação de água Biothec modelo BT80UR; (h) medidor de energia monofásico Hiking modelo DDS238-4; (i) plataforma elevatória; (j) frasco coletor

precisão Bel modelos 210A e M5202, cronômetro digital Cronobio SW-2018, termômetros Incoterm, densímetros Incoterm e refratômetro automático Anton Paar modelo Abbemat MW.

\section{Metodologias}

\section{Diagnósticos da gestão de resíduos}

Considerando-se que a recuperação de solventes já vigorava na Instituição, como parte da pesquisa proposta, delineou-se inicialmente a elaboração de uma entrevista estruturada, cujo direcionamento estava voltado para um público-alvo compreendido pelas pessoas que manipulavam solventes orgânicos em suas atividades. Todas as perguntas formuladas apresentavam alternativas de respostas, sendo permitido ao entrevistado a opção de responder, quando julgasse necessário, mais de uma resposta ou até mesmo citar outras além das disponibilizadas nos questionários. As questões formuladas objetivaram a compreensão de aspectos relacionados à identificação, segurança e gerenciamento (rotulagem, segregação, acondicionamento e armazenamento) dos solventes orgânicos, antes, durante e após seu manuseio, bem como quanto à aceitação de solventes orgânicos recuperados.

Avaliaram-se os históricos de geração de resíduos constituídos por solventes orgânicos, para identificar aqueles usados em maiores quantidades e os principais laboratórios usuários dos mesmos, onde posteriormente realizaram-se visitas para entrevistar funcionários, alunos (graduação e pós-graduação) e pós-docs que manipulavam solventes em suas pesquisas. De posse das respostas coletadas, buscou-se traçar um diagnóstico, que poderia ser confrontado com mapas anuais de aquisição de reagentes do mesmo período da realização da entrevista (2014 e 2015), e que são apresentados aos órgãos de fiscalização, no caso, a Divisão de Controle e Fiscalização de Produtos Químicos da Polícia Federal.

\section{Avaliação do processo de recuperação de acetona}

Para a avaliação das condições operacionais de recuperação, foi utilizado como referência nos testes de destilação o resíduo gerado no método de análise de alimentos (forrageiras) empregados na nutrição de animais ruminantes, também conhecido como análise de FDN (fibra em detergente neutro) e FDA (fibra em detergente ácido), cuja geração ocorre no Laboratório de Nutrição Animal do CENA. Os principais motivos para essa escolha residem na boa frequência de geração, no alto teor de acetona na composição do resíduo e no interesse em reutilizar o solvente por parte do laboratório gerador. Resumidamente, a referida análise consiste em determinar a parede celular insolúvel por meio da extração de constituintes do conteúdo celular solúvel em solução neutra de lauril sulfato de sódio e EDTA, denominada FDN. No resíduo dessa extração encontram-se proteínas insolúveis, que podem ser solubilizadas, assim como a hemicelulose, através de outro processo de extração denominado FDA, em que se utiliza o brometo de cetil-trimetilamônio e ácido sulfúrico. ${ }^{24} \mathrm{Ao}$ final de cada uma das duas etapas e após as amostras terem sido previamente lavadas em água, faz-se necessário o uso da acetona para uma última lavagem, que por sua vez é segregada e acondicionada em recipiente específico, gerando dessa forma uma solução residual cuja proposta de destinação é o processo de destilação.

Considerando-se a importância de se avaliar diversos parâmetros relacionados à operação do sistema de recuperação de solventes, vários ensaios foram propostos objetivando o estabelecimento das temperaturas ideais de aquecimento para a obtenção de solventes de elevada pureza, o que permitiria a otimização do consumo energético e, consequentemente, a redução nos custos e demanda por energia.

Para a avaliação da influência da temperatura de aquecimento das mantas no rendimento do processo de recuperação do solvente, vários testes foram realizados em cada uma das linhas (A e B) do sistema de destilação. Essa etapa teve a finalidade de estabelecer 
a condição mais adequada com o objetivo de obter um produto recuperado similar ao reagente P.A-A.C.S, considerando-se ainda o consumo de energia e o tempo necessário para o término do processo. Estabeleceu-se em cada teste a temperatura aferida no topo das colunas em $56{ }^{\circ} \mathrm{C}$ (valor aproximado ao ponto de ebulição da acetona) e a temperatura da água de recirculação do banho ultratermostatizado em $20^{\circ} \mathrm{C}$.

A massa de resíduo fixada em cada processo de destilação foi da ordem de $3.000 \mathrm{~g}$, sendo realizadas amostragens para permitir a realização de análises por cromatografia gasosa, refratometria e densimetria no produto recuperado final. Ao término da destilação, o líquido remanescente (sobra da destilação) foi pesado, em balança semi-analítica, para estimativa de balanço de massas nesse substrato.

O consumo de energia ( $\mathrm{kwh}$ ) em cada teste foi obtido com auxílio de um medidor de energia monofásico instalado ao sistema de destilação e ao banho ultratermostatizado. Para estimar os dispêndios na recuperação de cada quilograma de solvente, ponderou-se, além da demanda energética, os gastos com a depreciação dos equipamentos e hora/atividade do operador responsável pelo tratamento. O custo aferido, diretamente relacionado ao balanço de massas do processo, pôde ser comparado ao valor do reagente comercial P.A-A.C.S e aos gastos com uma eventual destinação dos resíduos para incineração, permitindo-se avaliar a economicidade das ações.

\section{Avaliação de parâmetros de qualidade}

Uma das maiores preocupações dos gestores de resíduos refere-se à eficiência da segregação dos solventes nos laboratórios geradores, evitando-se qualquer mistura indevida, que poderia resultar em contaminação do produto recuperado que, ao ser reutilizado, poderia levar a outras inconveniências (erros analíticos, contaminação de processos, etc). Nesse contexto, insere-se a aplicação de técnicas que possibilitem a separação e identificação dos constituintes presentes em amostras de interesse, sendo a cromatografia gasosa uma ferramenta apropriada para esse diagnóstico.

De forma a implementar o monitoramento em rotina da avaliação de parâmetros de qualidade dos solventes recuperados, houve a necessidade do estabelecimento de um método cromatográfico de análise, sendo que, para a realização das análises preliminares e o acompanhamento dos tempos de retenção, recorreu-se à injeção de acetona e demais solventes utilizados em rotina nos laboratórios do CENA (todos grau P.A-A.C.S), cuja circulação interna na forma de resíduos se mostrou mais frequente, substâncias essas que poderiam ser de interesse para fins de recuperação em caso de viabilidade operacional e interesse no reuso. Durante os testes, parâmetros como temperaturas do injetor, coluna (incluindo o estabelecimento de rampas de aquecimento) e detector, vazão do gás de arraste e tempo de análise foram avaliados. Com isso, foi possível estabelecer as melhores condições de trabalho e também criar um banco de dados referente aos tempos de retenção das moléculas orgânicas, auxiliando nas futuras identificações de rotina.

Adicionalmente às análises cromatográficas, também foram realizadas aferições de densidade e refratometria, o que permitiu estimar as concentrações do solvente $(\% \mathrm{~m} / \mathrm{m})$ nas amostras de interesse a partir da comparação de dados de tabelas referentes a mistura binárias entre água e acetona disponíveis na literatura. ${ }^{25}$

Com o intento de disponibilizar as informações da análise de pureza do solvente recuperado, preocupou-se com a elaboração de um laudo/FISPQ (Ficha de Informação de Segurança para Produtos Químicos) a ser fornecido junto ao produto no ato da entrega ao usuário. No laudo são apresentadas, além das condições do método e resultado cromatográfico, as informações sobre as características, riscos, medidas preventivas e remediativas para o manuseio do solvente.

\section{Comparação destilação x incineração}

Para o estudo da análise comparativa entre os tratamentos aplicáveis aos resíduos contendo solventes (destilação versus incineração), utilizou-se o software de fonte aberta Ecosolvent ${ }^{\circledR}$ v.1.0.1. Capello, Hellweg e Hungerbühler, criadores do software, referem-se ao mesmo como sendo uma ferramenta de avaliação de ciclo de vida. Esse processo permite uma comparação em termos ambientais, da destilação de soluções residuais de solventes, com tratamentos termais em incineradores industriais de produtos químicos ou fornos para produção de cimento (coprocessamento). ${ }^{20}$

Graças aos modelos de análise de inventário de ciclo de vida das referidas tecnologias de tratamento, informações sobre emissões de gases, geração de coprodutos, uso de insumos, entre outros impactos ambientais, são possíveis de serem calculadas. Os referidos modelos são baseados nos inventários disponibilizados pela Associação sem fins lucrativos Ecoinvent, representada atualmente por institutos do ETH Domain e pelo Swiss Federal Offices, cujos esforços possibilitam manter um banco de dados com várias publicações relacionadas a estudos sobre análise de ciclo de vida de diferentes processos industriais.

Para realizar a avaliação, considerou-se como unidade funcional a massa usada nos testes de destilação, ou seja, $3.000 \mathrm{~g}$ de resíduo contendo acetona. Dentre os indicadores ambientais disponibilizados pelo software para quantificação dos impactos, foi selecionado o Eco-indicator 99. Fornecendo os resultados em valores numéricos denominados ecopontos, o referido indicador quantifica os prejuízos à vida humana e ao meio ambiente provocados por todas as emissões e danos aos recursos naturais.

As demais informações necessárias para alimentar o software, como composição do resíduo, consumo de energia, quantidade e qualidade do solvente recuperado, distância percorrida no transporte dos resíduos para uma eventual incineração, entre outras, foram adquiridas, principalmente, a partir dos testes realizados. No que se refere às informações relacionadas à pré-tratamentos, usos de auxiliares (como por exemplo o uso de substâncias arrastadoras no caso de misturas azeotrópicas) e outras que não condiziam com a realidade da pesquisa, foram preenchidas como não utilizadas ou zeradas quando havia a necessidade de inserir valores numéricos.

\section{RESULTADOS E DISCUSSÃO}

\section{Diagnósticos da gestão de resíduos}

De forma a diagnosticar as etapas envolvidas na manipulação dos solventes e na gestão dos resíduos gerados, foram visitados os Laboratórios de Melhoramento de Plantas, Nutrição Animal, Ecotoxicologia, Radiobiologia e Ambiente, Carbono 14 e Biotecnologia Vegetal, tendo sido entrevistados colaboradores desses setores. Dentre as informações obtidas, pode-se destacar aquela que inventaria os solventes orgânicos usados nas rotinas em cada laboratório gerador de resíduos e cuja relação é discriminada na Tabela 1.

A Tabela 1 permite a identificação de quais solventes estão presentes nas atividades de cada laboratório, ainda que o volume utilizado não esteja sendo considerado. Com essa informação é possível realizar uma rápida comparação com os solventes mais usados identificados através dos históricos de geração de resíduos, que foram: acetona; acetonitrila; butanol; clorofórmio; diclorometano; etanol; isopropanol; metanol; e tolueno, notando uma clara coerência entre as informações.

Quando questionados sobre a frequência de retirada dos resíduos contendo solventes, $50 \%$ dos entrevistados não tinham certeza sobre essa informação, $31 \%$ responderam ser mensal e $19 \%$ quinzenal. A metade dos entrevistados que responderam não ter certeza é representada, em grande maioria por alunos, evidenciando um 
Tabela 1. Solventes utlizados em rotina e gerados como resíduos nos laboratórios do CENA/USP

\begin{tabular}{ll}
\hline Local & Solventes utilizados \\
\hline Lab. de Melhoramento de Plantas & Acetona, Metanol, Etanol, Isopropanol e Clorofórmio \\
Lab. de Nutrição Animal & $\begin{array}{l}\text { Acetona, Metanol, Etanol, Isopropanol, Butanol, Acetonitrila, Clorofórmio, Diclorometano, Tolueno, Éter etílico } \\
\text { e Acetato de Etila }\end{array}$ \\
Lab. de Ecotoxicologia & $\begin{array}{l}\text { Acetona, Metanol, Etanol, Clorofórmio, Isopropanol, Acetonitrila, Diclorometano, Tolueno, Hexano e Acetato } \\
\text { de etila }\end{array}$ \\
Lab. de Radiobiologia e Ambiente & Acetona, Metanol e Etanol \\
Lab. Carbono 14 & Acetona, Etanol, Tolueno, Benzeno, Tricloroetileno e Éter de petróleo \\
Lab. de Biotecnologia Vegetal & Etanol, Isopropanol e Clorofórmio \\
\hline
\end{tabular}

envolvimento quase que exclusivo dos funcionários no que se refere ao encaminhamento interno dos resíduos. É importante esclarecer que a remoção interna de resíduos na Instituição é realizada semanalmente, mediante solicitação por parte dos laboratórios geradores, ou seja, esses percentuais refletem a rotina da gestão desses resíduos. Por outro lado, é possível concluir que não ocorre um acúmulo muito grande de resíduos nos laboratórios geradores, estando as frequências citadas relacionadas com as diferentes demandas de análises. Isso pode ser considerado extremamente positivo e ocorre devido à existência de um Programa de Gerenciamento de Resíduos Químicos na Instituição que atua de forma dinâmica no manejo correto dos ativos gerados, tornando o acúmulo de passivos cada vez mais raro de ser encontrado.

O principal foco da entrevista foi a aceitação dos solventes recuperados, sendo que pouco mais da metade dos entrevistados (56\%) se demonstrou receptivo aos usos de tais substâncias. No que se refere aos motivos que justificariam a opção dos entrevistados que responderam não usar solventes recuperados, as principais justificativas são listadas na Figura 2. Resalta-se que o item "outros" nesta Figura refere-se a: experiências mal sucedidas decorrentes do uso de solventes recuperados, porém, caso houvesse uma análise da qualidade dessas substâncias, o problema poderia ter sido evitado; falta de disponibilidade do recuperado; e especificidade do protocolo analítico, que não permitiria o uso do solvente recuperado. Nesse contexto, percebe-se a importância de uma maior divulgação da possibilidade de recuperação de solventes em âmbito institucional, com ênfase na qualidade desses produtos recuperados. Obviamente, determinadas análises demandam um elevado grau de pureza em seus reagentes, o que inviabilizaria o uso dos solventes recuperados, mas para outras análises seria possível a realização de testes para verificação da possibilidade de seu uso, diminuindo dessa forma as restrições ao uso de tais produtos.

A aplicação do questionário permitiu também identificar em qual etapa de trabalho esses solventes estavam sendo reutilizados. Nota-se na Figura 3, que além da utilização na limpeza de materiais e vidrarias, que representa um uso menos nobre, tem-se um significativo

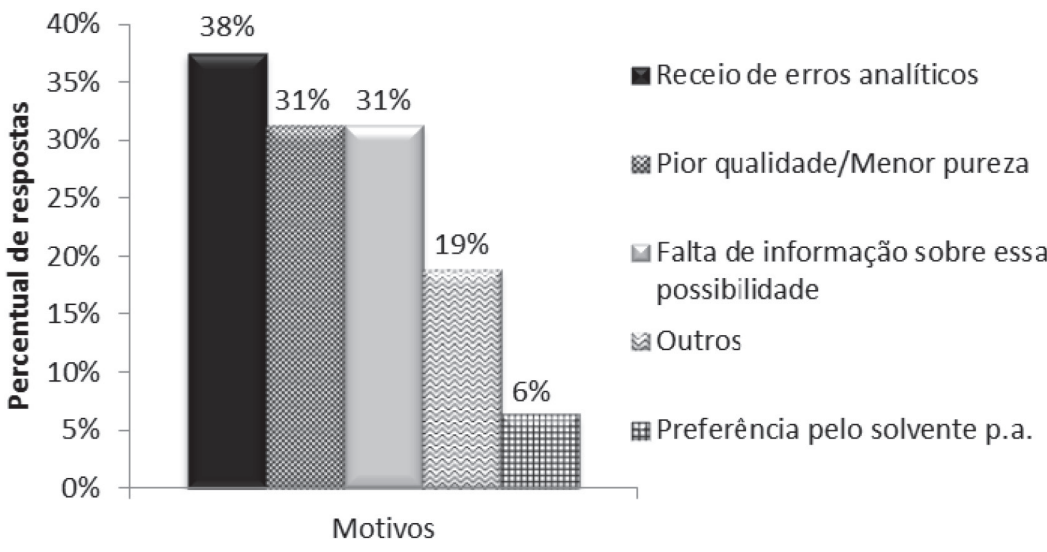

Figura 2. Justificativas apresentadas pelos entrevistados que declaram não utilizar solventes recuperados

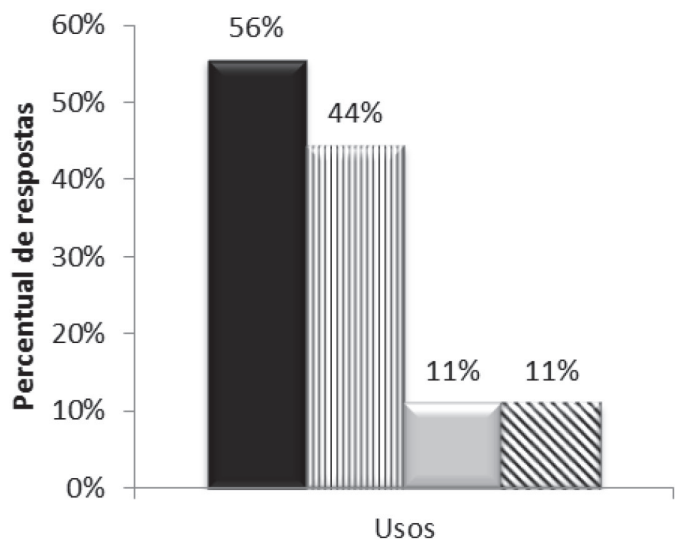

Limpeza de materiais e vidrarias

ill Protocolo analítico

$\square$ Preparo de amostra

s Outros

Figura 3. Principais usos de solventes recuperados nos laboratórios do CENA/USP 
Tabela 2. Quantidades de solventes adquiridos pelos laboratórios do CENA/USP e gerados como resíduos durante os anos de 2014 e 2015

\begin{tabular}{cccc}
\hline Ano & Solventes comprados $(\mathrm{L})$ & Resíduos Gerados $(\mathrm{L}) * * *$ & Solventes recuperados $(\mathrm{L})$ \\
\hline 2014 & $146,2^{*}$ & 508 & 139 \\
2015 & $49,5^{* *}$ & 444 & 81,5 \\
\hline
\end{tabular}

*Solventes adquiridos: acetona, clorofórmio, álcool butílico, tolueno, acetonitrila, etanol e éter de petróleo. **Solventes adquiridos: clorofórmio, diclorometano, hexano, acetato de etila, acetona, éter etílico e tolueno. ***Em relação aos resíduos gerados, os volumes representam o total da geração, incluindo misturas (como água).

uso em etapas de trabalho de processos analíticos. O item "Outros" na Figura 3 representa um uso específico em um banho criogênico (gelo seco + etanol). Como complemento, quando provocados a opinar sobre a qualidade desses produtos, a totalidade dos entrevistados respondeu ser satisfatória, o que serve para corroborar ainda mais a qualidade e o incentivo ao uso dos solventes recuperados.

Uma última etapa do diagnóstico envolveu o trabalho de coleta de dados junto ao Setor de Compras e Almoxarifado para fins de comparação com os registros de coleta de resíduos contendo solventes no mesmo período (2014/2015). Esses dados estão representados na Tabela 2 e ilustram um baixo volume de solventes comprados, principalmente no ano de 2015, enquanto o volume de resíduos coletados foi bastante superior. Essa diferença quantitativa pode ser explicada pela disponibilidade em estoque dessas substâncias nos laboratórios, evitando a necessidade de compras; por eventuais compras sem o conhecimento dos setores administrativo e financeiro da instituição (compra direta); ou por pesquisas realizadas em parceria com outras instituições, sendo os reagentes comprados com verba dessas instituições e os resíduos gerados no CENA. De todo modo, o referido diagnóstico é um indicador de que a gestão de compras e estocagem desses solventes é passível de aprimoramento, o que conduz a um cenário no qual a fiscalização pelos órgãos competentes (Policia Federal) tem se mostrado cada vez mais rígida. Para isso, se faz necessária a criação de mecanismos que possibilitem um real conhecimento das substâncias que entram na Instituição, como a criação de um sistema informatizado para pedidos de compras e um almoxarifado central para recebimento e estocagem dos produtos químicos, levando em consideração ainda a agilidade e a segurança no processo.

\section{Avaliação de parâmetros da qualidade}

Após a realização de diversos testes cromatográficos objetivando a definição de um protocolo analítico para uso em rotina e nos testes de interesse, estabeleceram-se como condições operacionais de trabalho os seguintes parâmetros: Temperatura do injetor $=200{ }^{\circ} \mathrm{C}$; Injeção modo Split na proporção $75: 1$; Programação da temperatura da coluna (HP INNOWAX) $=40{ }^{\circ} \mathrm{C}$ por $2 \mathrm{~min}, 15^{\circ} \mathrm{C} \mathrm{min}{ }^{-1}$ até $190{ }^{\circ} \mathrm{C}$; Temperatura do detector $=300{ }^{\circ} \mathrm{C}$; Vazão do gás de

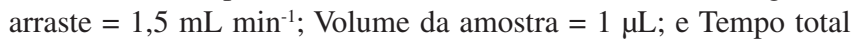
da análise: 12 minutos. A título de ilustração, a Figura 4 apresenta um cromatograma da acetona grau P.A-A.C.S com uma pureza de $99,978 \%$, obtido de acordo com as condições citadas acima e usado como referência para comparação nas análises de pureza do solvente recuperado.

Estabelecidas as condições analíticas, criou-se um banco de dados com os tempos de retenção dos principais solventes utilizados na Instituição (Tabela 3), para serem usados nas futuras identificações desses compostos em outras soluções residuais de interesse e, principalmente, para avaliar a eficiência do processo de destilação, analisando a presença dessas moléculas, assim como possíveis contaminantes no produto recuperado.

Nota-se, principalmente para os solventes metanol e diclorometano, assim como para clorofórmio e acetonitrila, que os tempos de retenção se mantiveram muito próximos, mesmo tendo sido testados outros valores de vazão do gás e de temperaturas de aquecimento do forno. O limitante nessa questão recai sobre a coluna usada, sendo a mesma não possuidora de comprimento e/ou espessura do filme suficientes para uma melhor separação dessas substâncias, porém,

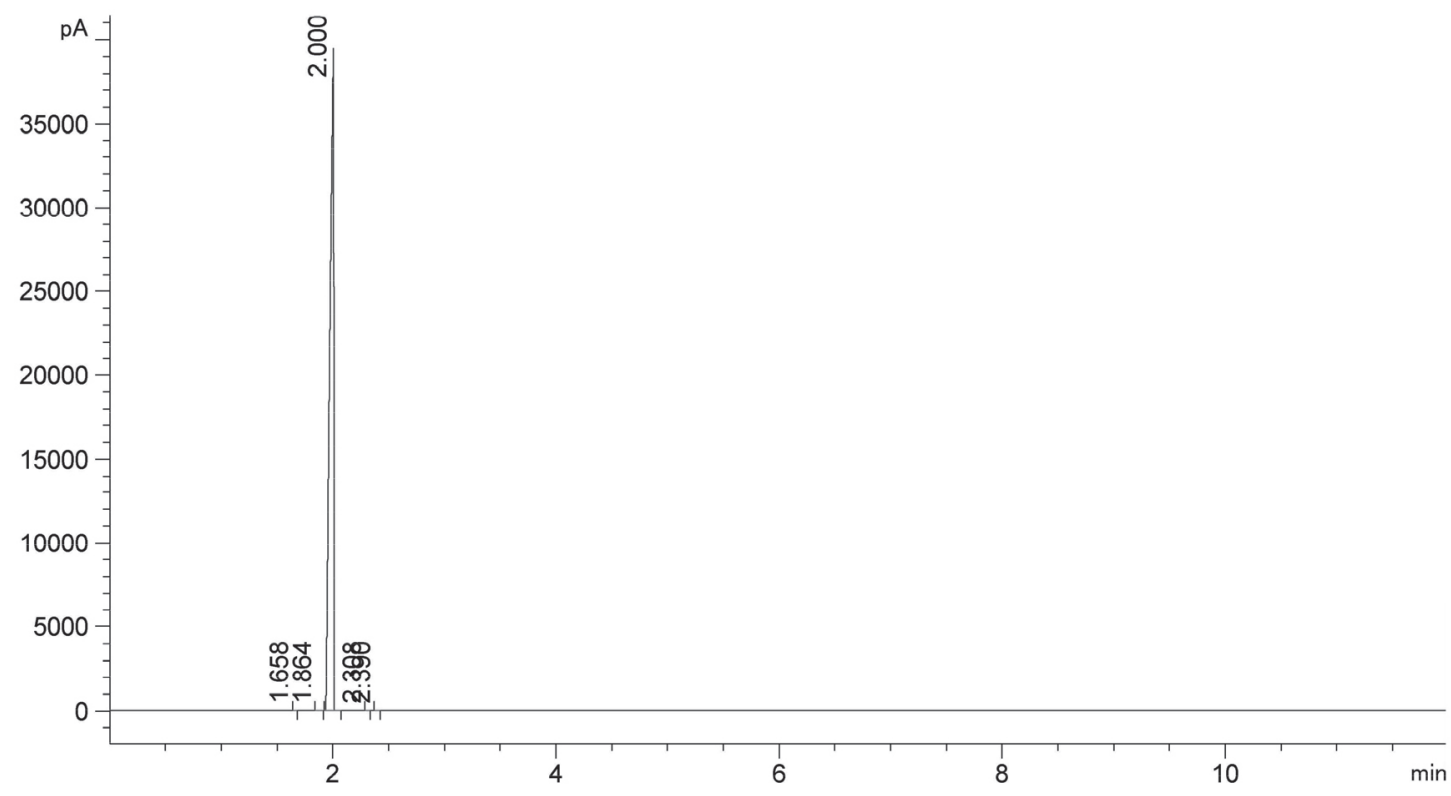

Figura 4. Cromatograma de acetona P.A-A.C.S nas condições definidas (Coluna HP-INNOWAX, $30 \mathrm{~m}$ x 0,25 mm, espessura do filme de 0,15 $\mu$ m; fase móvel: nitrogênio a 1,5 $\mathrm{mL}$. $\mathrm{min}^{-1}$; temperatura do injetor: $200{ }^{\circ} \mathrm{C}$; temperatura da coluna: $40{ }^{\circ} \mathrm{C}$ por 2 minutos a $190{ }^{\circ} \mathrm{C}$ a $15^{\circ} \mathrm{C}$ min ${ }^{-1}$; detecção por ionização em chama, $300^{\circ} \mathrm{C}$ ) 
Tabela 3. Tempo de retenção dos principais solventes usados pelos laboratórios do CENA/USP

\begin{tabular}{cc}
\hline Solvente & Tempo de retenção (minutos) \\
\hline Acetona & 2,000 \\
Diclorometano & 2,565 \\
Metanol & 2,584 \\
Isopropanol & 2,851 \\
Etanol & 2,907 \\
Acetonitrila & 3,528 \\
Clorofórmio & 3,537 \\
Tolueno & 3,877 \\
Butanol & 5,165 \\
\hline
\end{tabular}

isso não se tornou um fator agravante para o desenvolvimento da pesquisa.

Em relação aos demais parâmetros de qualidade, os resultados observados estão apresentados e discutidos à seguir, conjuntamente ao estudo das variáveis do processo de recuperação de solventes, utilizando-se acetona como matriz residual a ser destilada.

\section{Avaliação do processo de recuperação de acetona}

Em relação às temperaturas de aquecimento testadas em ambas linhas (A e B), foram notadas pequenas diferenças no tocante a pureza do solvente recuperado, evidenciando a eficiência do processo de purificação mesmo nas maiores temperaturas avaliadas. Já em relação aos valores aferidos de densidade, foi possível notar um moderado aumento conforme se aumentaram as temperaturas de aquecimento das mantas, evidenciando um crescente arraste indesejável de água junto à acetona. Em contrapartida, o aumento das temperaturas proporcionou menores tempos de destilação e consequentemente menores consumos de energia, mesmo com a elevação da potência do sistema de aquecimento.

A partir da tendência encontrada, segundo a qual aumentandose a temperatura ocorre diminuição na pureza, na concentração do solvente recuperado, no tempo de destilação, no consumo de energia e na perda de massa de acetona no processo, elegeu-se como melhor condição operacional as temperaturas mínimas de aquecimento que permitiram atingir os $56^{\circ} \mathrm{C}$ no topo das colunas das linhas A e B, as quais foram utilizadas nos testes comparativos, realizados em triplicatas. Mesmo não havendo sido encontradas diferenças muito acentuadas entre os parâmetros avaliados, a opção pelo uso dessas temperaturas permitiria a obtenção de um produto recuperado com excelente pureza em um período de tempo que não ultrapassasse 6 horas de destilação. Na Tabela 4 constam os principais parâmetros mensurados operando-se simultaneamente as duas linhas na destilação de um resíduo com concentração de acetona de $59 \%(\mathrm{~m} / \mathrm{m})$ e densidade de $0,911 \mathrm{~g} \mathrm{~mL}^{-1}$ a $21^{\circ} \mathrm{C}$. Ressalta-se que, nesssas condições, o consumo total de energia aferido foi de $3,8 \mathrm{kwh}$.

Na aferição do balanço energético no processo, comparando-se a operação das linhas A e B operando individual ou simultaneamente, tem-se nessa última condição uma diminuição do consumo de energia em $27 \%$, mantendo os mesmos valores de pureza e concentração do produto recuperado. Isso ocorre devido ao melhor aproveitamento do banho ultratermostatizado, já que o mesmo promove a recirculação da água nas duas linhas, independente de qual esteja em funcionamento.

As análises cromatográficas e de densidade comprovaram a elevada qualidade possível de se obter em um solvente recuperado pelo processo de destilação avaliado, assegurando-se a obtenção de
Tabela 4. Desempenho do processo de destilação e parâmetros de qualidade da recuperação de acetona obtidos com as duas linhas do sistema de destilação operando simultaneamente

\begin{tabular}{lcc}
\hline Parâmetro & \multicolumn{2}{c}{ Resultados } \\
\hline Linha de destilação & $\mathrm{A}$ & $\mathrm{B}$ \\
Massa do resíduo $(\mathrm{g})$ & $2.999,95$ & $2.999,93$ \\
Tempo de destilação (min) & 330,38 & 260,85 \\
Pureza do recuperado (\%) & 99,843 & 99,836 \\
Concentração de acetona no recuperado $(\%)$ & 97,9 & 97,9 \\
Densidade do recuperado $\left(\mathrm{g} \mathrm{mL} \mathrm{mL}^{-1}\right)$ à $20^{\circ} \mathrm{C}$ & 0,797 & 0,797 \\
Índice de refração à $20^{\circ} \mathrm{C}$ & 1,359791 & 1,359799 \\
Massa do recuperado $(\mathrm{g})$ & $1.513,43$ & $1.510,33$ \\
Fração de acetona na sobra da destilação $(\%, \mathrm{~m} / \mathrm{m})$ & 15,6 & 16,4 \\
Densidade da sobra da destilação $\left(\mathrm{g} \mathrm{mL}^{-1}\right)$ à $2{ }^{\circ} \mathrm{C}$ & 1,004 & 1,002 \\
Massa da sobra da destilação $(\mathrm{g})$ & $1.426,68$ & $1.441,37$ \\
Perda de massa $(\mathrm{g})$ & 59,84 & 48,23 \\
\hline
\end{tabular}

um produto livre de contaminantes que possam causar interferências nos procedimentos em que o produto seja empregado. Por sua vez, quando se avaliou o índice de refração nas amostras de solvente recuperado nas linhas A e B, obteve-se diagnóstico semelhante, visto que o índice de refração da acetona é da ordem de 1,3588 $\mathrm{nD}\left(20{ }^{\circ} \mathrm{C}\right),{ }^{26}$ valor esse muito próximo ao encontrado nos testes realizados. Tendo como referência os resultados desse parâmetro, permite-se estimar em aproximadamente $98 \%$ a concentração de acetona nos solventes, através da relação direta com os índices de refração de misturas binárias de acetona e água. ${ }^{25}$ Tal concentração é equivalente àquela possível de ser estimada a partir da densidade do solvente recuperado.

No que se refere à estimativa dos custos envolvidos no processo de destilação, tem-se os parâmetros fixos e variáveis. O custo de aquisição do sistema dedicado para destilação, composto pelas duas linhas e banho de circulação ultratermostatizado, é da ordem de $\mathrm{R} \$ 19.000,00$ (US\$4,935.00). Fixou-se para esse conjunto uma vida útil estipulada em 20 anos. Visando o aproveitamento máximo do sistema, considerou-se que ao longo do período estipulado, o mesmo estaria em operação todos os dias úteis com as duas linhas trabalhando simultaneamente e destilando uma massa de $3 \mathrm{~kg}$ de resíduo por linha/dia. Para fins de tabulação, na operação do sistema de destilação mais as realizações das análises, considerou-se a dedicação de 30 minutos diários de um técnico de laboratório com salário mensal de $\mathrm{R} \$ 3.933,26$ e fixou-se em $\mathrm{R} \$ 0,50$ por kwh o valor da tarifa cobrada pela concessionária responsável pelo fornecimento de energia. Como simulação desse cenário, em período de 20 anos, a Tabela 5 resume as informações utilizadas nos cálculos de interesse.

A soma dos valores contabilizados nos parâmetros acima elencados totaliza $\mathrm{R} \$ 83.896,00$, o que resulta em estimativa de custo da ordem de $\mathrm{R} \$ 5,50$ para cada quilograma de acetona recuperada. Comparando esse valor com o custo de aquisição de $1 \mathrm{~kg}$ do produto comercial, na ordem de $\mathrm{R} \$ 35,00$ (com base no valor de $\mathrm{R} \$ 28,00$ o litro), mais o custo do encaminhamento da mesma massa de resíduo para incineração no valor de $\mathrm{R} \$ 10,00$, conclui-se que o custo da destilação é cerca de 8 vezes menor que o da compra do produto somada à incineração do resíduo. Ressalta-se, ainda, que seria possível economizar $\mathrm{R} \$ 39,50$ por cada quilograma recuperada, ou $\mathrm{R} \$ 119,00$ a cada batelada diária, permitindo que o custo da aquisição de um sistema completo de destilação como esse seja pago em 160 dias úteis ou 8 meses. 
Tabela 5. Estimativa da massa de solvente recuperado e consumo de energia considerando a capacidade máxima de operação do sistema de destilação ao longo de 20 anos

\begin{tabular}{lc}
\hline Dados & Quantidade \\
\hline Dias úteis (20 anos) & 5.070 \\
Massa recuperada por dia (kg) & 3,0 \\
Massa recuperada (kg em 20 anos) & 15.210 \\
Consumo de energia por dia (kwh) & 3,8 \\
Consumo de energia (kwh em 20 anos) & 19.266 \\
\hline
\end{tabular}

\section{Comparação destilação $x$ incineração}

Para quantificação dos impactos ambientais da destilação pelo Ecoindicator 99 foram consideradas as seguintes informações: processo único em batelada; sem a realização de pré-tratamentos; sem uso de auxiliares; destinação da sobra da destilação para estação de tratamento de esgoto (considerou-se essa alternativa de encaminhamento para o resíduo utilizado na pesquisa, pois sua composição é compreendida majoritariamente por água, não apresentando compostos com potenciais de causarem danos a rede de esgoto e ao meio ambiente, não sendo recomendada esta destinação para todas as sobras provenientes da destilação de demais resíduos com diferentes composições); sem transporte dos resíduos até o destilador; absorção como tratamento para os vapores orgânicos emitidos; dados obtidos durante os testes realizados (consumo de energia, quantidade e qualidade do solvente recuperado). Para a incineração, considerou-se os impactos provenientes de incinerador industrial de produtos perigosos e com uma distância de 170 $\mathrm{km}$ percorrido no transporte do resíduo (equivalente à distância entre Piracicaba e Taboão da Serra, principal destino dos resíduos perigosos enviados pelo CENA/USP para fins de incineração).

Os resultados apresentados na Figura 5 trazem a comparação entre o dois tratamentos aplicáveis, sendo os resultados positivos representativos de encargos ambientais e os resultados negativos representativos de créditos ambientais. Nota-se, no caso da destilação, indicada pela letra $\mathrm{D}$, apenas a contabilização dos impactos em D1, pois os tratamentos realizados sempre ocorreram em apenas uma etapa, sendo D2 representativo de uma possível segunda etapa de destilação. A Tabela 6 apresenta os ecopontos em valores numéricos para os principais parâmetros considerados.

$\mathrm{O}$ indicador utilizado aponta para a destilação do resíduo como sendo o tratamento mais sustentável, tendo como principal vantagem a compensação dos impactos causados durante a produção do solvente quando o mesmo é recuperado. Com relação à incineração, esse tratamento se mostrou mais impactante devido principalmente ao transporte dos resíduos, além dos impactos provenientes da produção do solvente. É importante ressaltar que o impacto poderia ser menor caso a energia liberada pela queima dos resíduos fosse convertida em eletricidade, como acontece em incineradores de produtos perigosos localizados em países europeus, diferentemente da realidade brasileira.

Com o uso do Ecosolvent, Amelio et al. ${ }^{19}$ concluíram que os impactos originados durante a produção do solvente devem ser a principal questão a ser observada para a escolha de qual método de tratamento será aplicado ao resíduo. De forma geral, os autores sugerem que os solventes que apresentam baixos impactos ambientais de produção são candidatos a serem incinerados, já aqueles que apresentam altos valores de danos ambientais devem ser recuperados em vistas a diminuir seus impactos totais. Porém, há de se levar em

Tabela 6. Comparação dos impactos ambientais em valores numéricos de ecopontos referentes ao tratamento de $3 \mathrm{~kg}$ de resíduo

\begin{tabular}{lcc}
\hline Parâmetro & Destilação & Incineração \\
\hline Produção & 0,712 & 0,712 \\
Energia & 0,019 & 0 \\
Auxiliares & 0 & 0,057 \\
Resíduos e emissões & 0,012 & 0,034 \\
Recuperação & $-0,658$ & 0 \\
Transporte & 0 & 3,647 \\
\hline Total & $\mathbf{0 , 0 8 5}$ & $\mathbf{4 , 4 5}$ \\
\hline
\end{tabular}

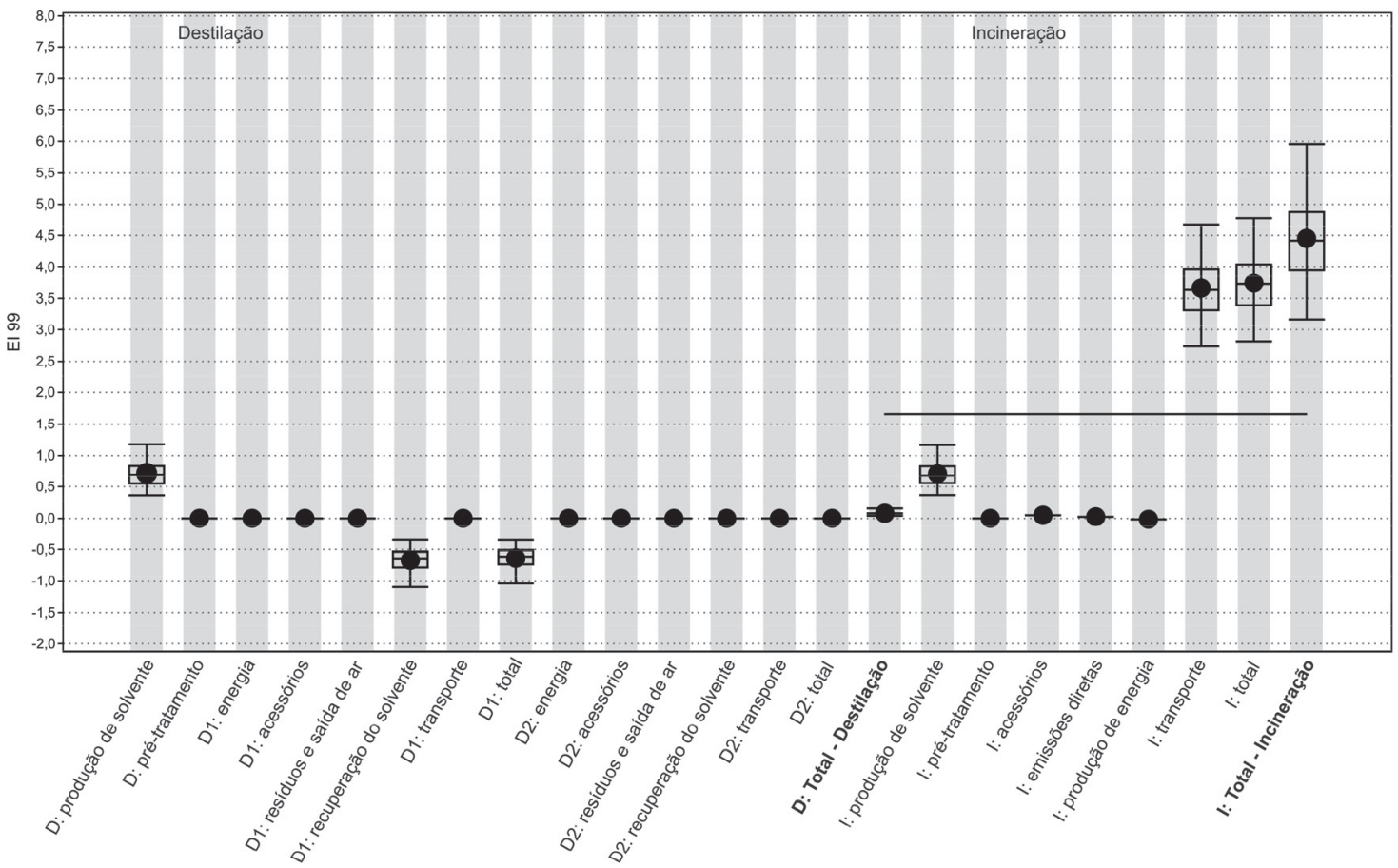

Figura 5. Comparação dos impactos ambientais pelo Eco-indicator 99 entre destilação e incineração obtidos pelo software Ecosolvent 
consideração a distância percorrida no transporte, pois como foi possível notar, os impactos decorrentes dessa etapa apresentaram uma grande contribuição para os impactos totais da incineração.

\section{CONCLUSÃO}

Primeiramente, deve-se destacar a importância que deve ser dada ao acompanhamento do fluxo dos reagentes em âmbito instituicional, o que inclui desde a programação para compra até a destinação final ambientalmente adequada dos resíduos gerados, resultando em ações continuadas que permitam aprimorar procedimentos atrelados ao gerenciamento.

Com base nos testes de destilação realizados em cada linha, foi possível encontrar vantagens e desvantagens com o aumento/diminuição da temperatura de aquecimento das mantas, ficando a cargo do operador estabelecer aquela condição que mais se encaixe nas suas necessidades, sendo preferível optar pelo uso das duas linhas ligadas ao mesmo tempo (desde que haja volume de resíduo suficiente) para otimização do consumo energético do processo. Considerando-se essa otimização e os custos operacionais envolvidos, foi possível estimar em apenas R $\$$ 5,50 a despesa para a obtenção de $1 \mathrm{~kg}$ de acetona recuperada.

A partir da implantação da análise por cromatografia gasosa do solvente recuperado, em conjunto com as aferições de densidade e índice de refração, constatou-se a eficiência do processo, mesmo nas temperaturas mais elevadas, tornando possível observar a alta qualidade desses produtos, servindo de estímulo quanto à aceitação para fins de reaproveitamento interno.

No que diz respeito à comparação entre as duas formas de tratamento para os resíduos constituídos de solventes, os resultados obtidos corroboram as vantagens econômicas e ambientais em se destilar esses resíduos ao invés de incinerá-los, devendo-se avaliar, concomitantemente, o interesse em reuso desses solventes por parte dos usuários dos laboratórios e a própria composição desses resíduos, evitando-se a indesejável presença de substâncias termicamente instáveis e outras que possam interferir no processo de recuperação.

Por fim, permite-se concluir que a recuperação de solventes deve ser estimulada em âmbito institucional, o que também é prática corrente em outras Instituições. ${ }^{7,9,23,27,28}$

\section{AGRADECIMENTOS}

Os autores agradecem ao CNPq e à CAPES pelo auxilio financeiro, ao Sr. João Geraldo Brancalion do CENA/USP pelo apoio na diagramação das figuras e à Dra. Patrícia Busko Di Vitta do IQ/USP pela valiosa discussão e sugestões por ocasião do desenvolvimento da pesquisa.

\section{REFERÊNCIAS}

1. Jardim, W. F.; Quim. Nova 1998, 21, 671.

2. Amaral, S. T.; Machado, P. F. L.; Peralba, M. C.; Camara, M. R.; Santos, T.; Berleze, Ava. L.; Falcão, H. L.; Martinelli, M.; Gonçalves, R. S.; Oliveira, E. R.; Brasil, J. L.; Araújo, . A.; Borges, A. C. A.; Quim. Nova 1998, 24, 419 .
3. Cunha, C. J.; Quim. Nova 2001, 24, 424.

4. Alberguini, L. B. A.; Silva, L. C.; Rezende, M. O. O.; Quim. Nova 2003, 26, 291.

5. Afonso, J. C.; Noronha, L. A.; Felipe, R. P.; Freidinger, N.; Quim. Nova 2003, 26, 602 .

6. Tavares, G. A. ; Bendassolli, J. A.; Quím. Nova 2005, 28, 732.

7. Levada, J. Dissertação de Mestrado, IQSC, 2008, 60p.

8. Mistura, C. M.; Vaniel, A. P. H.; Linck, M. R. Revista CIATEC 2010, 2 , 54.

9. Cooper, M.; Meira, A. M.; Masetto, A. V.; Silva, A. R.; Ferraz, E. M.; Gonçalves, R. H. Em Gestão de resíduos em universidades; De Conto, S. M., ed.; Educs: Caxias do Sul, 2010.

10. Bendassolli, J. A; Mortatti, J.; Trivelin, P. C. O.; Ignoto, R. F.; Bonassi, J. A.; Tavares, G. A. Quím. Nova 2002, 25, 312.

11. Bendassolli, J. A.; Tavares, G. A.; Ignoto, R. F.; Rosseti, A. L. R. M. Quím. Nova 2003, 26, 578.

12. Bendassolli, J. A.; Maximo, E.; Tavares, G. A.; Ignoto, R. F. Quím. Nova 2003, 26, 612 .

13. Tavares, G. A; Bendassolli, J. A.; Souza, G.; Nolasco, F. R.; Bonassi, J. A.; Batagello, H. H. Quím. Nova 2004, 27, 320.

14. Tavares, G. A.; Giovannini, J. G.; Tavares, C. R. O.; Bendassolli, J. A. Revista Analytica 2006, 22, 66

15. Giovannini, J. G.; Tavares, G. A.; Bendassolli, J. A. Quím. Nova 2008, $31,676$.

16. Possignolo, N. V.; Tavares, G. A.; Oliveira, J. G. G.; Xavier, T. M. R.; Bendassolli, J. A. Revista Analytica 2009, 42, 94.

17. Oliveira, J. G. G. Dissertação de Mestrado, Universidade de São Paulo, Brasil, 2010.

18. http://www.planalto.gov.br/ccivil_03/_ato2007-2010/2010/lei/112305. htm, acessado em Outubro 2018

19. Amelio, A.; Genduso, G.; Vreysen, S.; Luis, P.; Van der Bruggen, B.; Green Chem. 2014, 16, 3045.

20. Capello, C.; Hellweg, S.; Badertscher, B.; Betschart H.; Hungerbühler, K.; J. Ind. Ecol. 2007, 11, 26.

21. Capello, C.; Hellweg, S.; Hungerbühler, K.; J. Ind. Ecol. 2008, 12, 111.

22. Luis, P.; Amelio, A.; Vreysse, S.; Calabro, V.; Van der Bruggen, B.; Int. J. Life Cycle Assess. 2013, 18, 1048.

23. Martins, C.; Di Vitta, P.; Marzoratti, L.; Di Vitta, C. Quim. Nova 2016, 11,856 .

24. Lourenço, M. S. N.; Tese de Doutorado, Universidade Estadual Paulista, Brasil, 2010.

25. Kurtz, S. S.; Wikingsson, A. E.; Camin, D. L.; J. Chem. Engineer. Data 1965, 10, 330 .

26. Haynes, W. M.; Handbook of Chemistry and Physics, $97^{\text {th }}$ ed., CRC Press: Boca Raton, 2016.

27. Campani, D. B.; Peralba, M. C. R.; Schmidt, V.; Loguercio, A. P.; Winckler, M. M.; Trein, M. R.; Oliveira, G. V.; Bazzo, A.; Santos, M. A. V.; Heitling, R. A. K. Em Gestão de resíduos em universidades; De Conto, S. M., ed.; Educs: Caxias do Sul, 2010.

28. www.ggus.depi.unicamp.br/old/site/premiogestaoambiental/PlantaPiloto-Premio-Gestao_IQ.pdf, acessada em Março 2019. 